\title{
The role of the Renal Disaster Relief Task Force
}

\author{
Raymond Vanholder, Mehmet S Sever and Norbert Lameire
}

The observations made in the aftermath of the Armenian earthquake of 1988 underscored the need for preplanned logistic organization to improve the outcomes of disaster victims with renal problems. As a result of extensive skeletal muscle trauma, victims trapped under the rubble of fallen buildings can develop socalled 'crush syndrome', which can in turn lead to acute kidney injury. Although crush syndrome affects a deceptively small fraction of disaster victims, this condition-which is reversible if treated properly-is the second leading cause of death following disasters, after death due to direct trauma. The expression 'renal disaster' has been introduced to describe natural and man-made events that are associated with a high incidence of crushinduced acute kidney injury (Solez $\mathrm{K}$ et al. [1993] Kidney Int 44: 479-483).

In 1989, the International Society of Nephrology established the Renal Disaster Relief Task Force (RDRTF) to offer support in disaster areas where renal injury or disease is a concern. The RDRTF's main focus is the treatment of acute kidney injury caused by natural disasters, although the Task Force has also helped provide care for patients with chronic kidney disease, particularly during man-made disasters, such as the Israel-Lebanon war of 2006.

The RDRTF is organized into regional divisions responsible for renal disaster rescue networks in three areas of the globe (Northern, Central and South America; South-East Asia; and Europe). The RDRTF's European division, which also oversees operations in Turkey, the Middle East and Africa, has to date been the most active. At the Task Force's headquarters, the RDRTF keeps lists of volunteer physicians, nurses and technicians who can be mobilized on short notice. In response to crises,

\section{... establish- ment of permanent networks for renal support \\ in severe \\ disasters and detailed a priori \\ planning can save the lives of [many]...}

\section{$R$ Vanholder is} Professor of Medicine at Ghent University and Head of the Nephrology Section at the University Hospital of Ghent, Ghent, Belgium; MS Sever is Professor of Medicine at Istanbul University and Head of the Nephrology Section at the Istanbul School of Medicine, Istanbul, Turkey; and N Lameire is Professor Emeritus in the Nephrology Section at the University Hospital of Ghent, Ghent, Belgium.

\section{Competing interests}

The authors declared no competing interests.

www.nature.com/clinicalpractice doi:10.1038/ncpneph0862
Médecins Sans Frontières (Doctors Without Borders), the nongovernmental relief organization with which the RDRTF operates, purchases the drugs needed to confront the renal disaster from the pharmacy of the University Hospital of Ghent, where the RDRTF's actions are coordinated. Dialysis equipment is stored ready for shipment in Médecins Sans Frontières' warehouses. Additional pharmaceuticals and dialysis equipment are purchased from or donated by manufacturers with which the RDRTF is in contact.

The 1999 Marmara earthquake in Turkey, the 2003 Bam earthquake in Iran, and the 2005 Kashmir earthquake were all renal disasters that necessitated extensive nephrological intervention. The RDRTF lent its support in several ways: sending medical personnel to the affected areas to help local doctors and nurses; giving logistic advice on how to handle and distribute medical supplies; providing medical and technical information including organizing teaching sessions on the treatment of crush syndrome and acute kidney injury; offering psychological support to victims as well as to medical and paramedical staff; and supplementing locally available dialysis hardware.

Even though the occurrence of disasters is unpredictable, the combination of population growth, increasing urbanization, persistent political instability and climate change make it unlikely that the number of catastrophes that necessitate renal intervention will decrease in the near future. The experience of the RDRTF has shown that the establishment of permanent networks for renal support in severe disasters and detailed a priori planning can save the lives of a substantial number of people (Sever MS et al. [2006] N Engl J Med 354: 1052-1063).

Further information on the RDRTF can be obtained by emailing rdrtf@ugent.be. 